Original Research Paper

\title{
Investigation of Quantitative Plant Activity Relationship (QPAR) for Diabetics II Using Genetic Algorithm
}

\author{
${ }^{1}$ Simanta Kumar Nayak, ${ }^{2}$ Bikram Kesari Ratha, \\ ${ }^{3}$ Payodhar Padhi, ${ }^{4}$ Santosh Kuamr Nanda and ${ }^{5}$ Aparajeya Panda \\ ${ }^{1,4}$ Eastern Academy of Science and Technology, Prachi Vihar, Phulnakhara, Bhubaneswar, Odisha, India \\ ${ }^{2}$ Utakal University, Bhubaneswar, Odisha, India \\ ${ }^{3}$ Research and Development Center, Hi-Tech Medical College and Hospital, Bhubaneswar, Odisha, India \\ ${ }^{5}$ Konark Institute of Science and Technology, Techno Park, Jatni, Bhubaneswar, Odisha, India
}

\author{
Article history \\ Received: 24-09-2012 \\ Revised: 13-11-2014 \\ Accepted: 18-03-2015 \\ Corresponding Author: \\ Santosh Kuamr Nanda \\ Eastern Academy of Science \\ and Technology, Prachi Vihar, \\ Phulnakhara, Bhubaneswar, \\ Odisha, India \\ Email: santoshnanda@live.in
}

\begin{abstract}
The present study demonstrates a novel computational approach for Indian Traditional Medicine (ITM) for the effective antidiabetic drug. Indian traditional practitioners are using many natural Herbals for the cure of diabetes. Though many diabetes patients are getting temporarily cured still its cause and effects are unknown due to lack of proper scientific investigation. Individual plant bioactivities have been already investigated by many researchers but the combined plant bioactivity effects have not been studied yet because it requires more number of experiments which is time consuming and expensive. Regular diabetic medicines available in the market still not based on the optimal plant bioactivity database and as a result of which the effectiveness of the medicine also reduced. To overcome the above drawback a novel computational approach was proposed for multiple antidiabetic plants in appropriate proportions for its optimization. Since the process is stochastic in nature Genetic Algorithm (GA) tool was selected for the design. The actual and predicted results have been compared in this study.
\end{abstract}

Keywords: Herbal Drugs, GA

\section{Introduction}

In the last few years there has been enormous growth in the field of herbal medicine and these drugs are gaining popularity both in developing and developed countries because of their natural origin and less side effects (Kavimanib et al., 2008). Many traditional medicines are derived from medicinal plants, minerals and organic matter (Chan et al., 2010). A number of medicinal plants, traditionally used for more than 1000 years named Rasayana are present in herbal preparations of Indian traditional health care systems (Dixit et al., 1986). In Indian systems of medicine, most practitioners formulate and dispense their own recipes (Grover et al., 2002). Major hindrance in amalgamation of herbal medicine in modern medical practices is lack of scientific and clinical data proving their efficacy and safety. There is a need for conducting clinical research in herbal drugs, developing simple bioassays for biological standardization, pharmacological and toxicological evaluation and developing various animal models for toxicity and safety evaluation
(Heacht, 2002). It is also important to establish the active component/s from these plant extracts.

Drug discovery is a most complex and costly process which involves more time for making and testing New Composition Entities (NCE). The average cost of creating NCE in a pharmaceutical company was estimated about \$1500/compound (Holland, 1975). Generally, herbal medicine is not composed of several herbs in appropriate proportion. The constituent of herbs and their proportion of certain herbal medicine are determined according to traditional medical knowledge. Unlike modern drugs in the form of single chemical ingredient, herbal medicine may contain hundreds of chemical compounds. Many researchers believe that synergistic effect of different active ingredients contributes to the therapeutic effect of herbal medicine (Ivorra et al., 1989). Modern clinical trial has proved that herbal drug composed of multiple herbs with multiple compounds in certain proportion has greater efficacy than a single herb. Therefore, modern herbal drug can be produced as a combination of different active 
components from herbs. However, the complex chemical composition of herbal medicine leads to the lack of appropriate method for identifying active compounds and optimizing the formulation of herbal medicine. The variation of biologic activity of herbal medicine is tightly associated with the variation of their chemical composition in the plant. Such relationship between chemical composition and biological activity is regarded as Quantitative Composition-Activity Relationship (QCAR) (Wang et al., 2006). By quantitatively analyzing the chemical composition and bioactivity relationship, a herbal medicine can be developed. But to isolate the chemical compounds from the individual plant and to study its individual bioactivities is a very difficult and time consuming task. Moreover, to prepare a drug in this manner is extremely difficult, which enables us to integrate different active components to form a more effective herbal drug. Further when a multiple herbals are mixed for the treatment of a disease it is very difficult to know the ratios for its optimum bioactivities. Hence in the present study, a computational approach has been proposed to model the Quantitative Plant Activity Relationship (QPAR) to predict the bioactivity of herbal drug in designing a new herbal drug for a specific disease. Here the disease is chosen is the most common disease i.e., Diabetics II.

\section{Methodology for the Proposed Work}

Quantitative plant-bioactivity relationship is the correlation between weight of plant parts used and its combined biological activity. Individual plant has certain biological activity, when the number of plants increases its activity may vary. Suppose a natural medicine $\mathrm{N}$ is composed of several kinds of plants and have a total weight $\mathrm{W}_{\mathrm{N}}$. This formulation can be divided into $n$ kinds of different plants i.e., $P_{i}(i=$ $1,2 \ldots . n)$ with an individual yield rate i.e., $Y_{i}(i=$ $1,2 \ldots . n)$. Thus the weight of each plant fraction can be represented as $\mathrm{Pi}=\mathrm{W}_{\mathrm{N}} * \mathrm{Y}_{\mathrm{i}}$. $(\mathrm{i}=1,2 \ldots \ldots n)$. The biological activity of the plant depends on the dose which has been determined by virtue of the experienced traditional practitioner. But when the number of plants increases to certain appreciable sizes, it becomes difficult to study.

In the present study 11 different antidiabetic plants were taken and the biological activity i.e., reduction of blood sugar level were given in Table 1 from the literature. The plants given in the Table 1 were mixed in different ratios keeping the total weight constant. Seven such mixed drugs have been formulated and their combined biological activities have been evaluated by animal trial given in Table 2 .

Table 1. Bioactivity of individual plants

\begin{tabular}{|c|c|c|c|c|c|c|}
\hline Plant name & Dosage & Time & Maximum & Minimum & $\begin{array}{l}\text { Bioactivity } \\
(\% \text { of reduction in } \\
\text { blood glucose level) }\end{array}$ & Reference \\
\hline Cajanus cajan & $600 \mathrm{mg} \mathrm{kg}^{-1}$ & $4 \mathrm{~h}$ & $364.0 \pm 29.1$ & $70.20 \pm 6.85$ & 80.70 & Ezike et al. (2010) \\
\hline Abrus precatorious & $50 \mathrm{mg} \mathrm{kg}^{-1}$ & $30 \mathrm{~h}$ & $261.50 \pm 2.08$ & $81.00 \pm 2.56$ & 69.10 & Monago and Alumanah (2005) \\
\hline Acacia polycantha & $400 \mathrm{mg} \mathrm{kg}^{-1}$ & $8 \mathrm{~h}$ & $360.80 \pm 48.74$ & $161.20 \pm 22.54$ & 67.90 & Okpanachi et al. (2010) \\
\hline Ficus arnottiana & $100 \mathrm{mg} \mathrm{kg}^{-1}$ & $2 \mathrm{~h}$ & $240 \pm 4.5$ & $116 \pm 1.35$ & 51.00 & Mazumder et al. (2009) \\
\hline Gmelina asiatica & $500 \mathrm{mg} \mathrm{kg}^{-1}$ & $4 \mathrm{~h}$ & $334.8 \pm 23.9$ & $213.9 \pm 14.4$ & 36.10 & Routhu et al. (2005) \\
\hline Ficus racemosa & $400 \mathrm{mg} \mathrm{kg}^{-1}$ & $3 \mathrm{~h}$ & $304.8 \pm 1.3$ & $120.3 \pm 2.7$ & 60.50 & Sachan et al. (2009) \\
\hline Piper betle & $200 \mathrm{mg} \mathrm{kg}^{-1}$ & $4 \mathrm{~h}$ & $230.2 \pm 16.2$ & $154.8 \pm 20.3$ & 32.70 & Arambewela et al. (2005) \\
\hline Azadirachta indica & $200 \mathrm{mg} \mathrm{kg}^{-1}$ & $6 \mathrm{~h}$ & $301.2 \pm 18.3$ & $162.8 \pm 2.3$ & 48.40 & Dixit et al. (1986) \\
\hline Coccinia indica & $400 \mathrm{mg} \mathrm{kg}^{-1}$ & $4 \mathrm{~h}$ & 254 & 59 & 76.70 & Niedzielski and Swift (2002) \\
\hline Phyllanthus emblica & $200 \mathrm{mg} \mathrm{kg}^{-1}$ & $2 \mathrm{~h}$ & $209 \pm 5.8$ & $90.6 \pm 8.7$ & 56.60 & Qureshi et al. (2009) \\
\hline Thespesia populnea & $300 \mathrm{mg} \mathrm{kg}^{-1}$ & $6 \mathrm{~h}$ & $290.54 \pm 1.66$ & $151.34 \pm 2.56$ & 47.91 & Satyanarayana et al. (2004) \\
\hline
\end{tabular}

Table 2. Actual and predicted bioactivity of individual optimized drugs and their compositions

\begin{tabular}{|c|c|c|c|c|c|c|c|c|c|c|c|c|c|}
\hline \multirow[b]{2}{*}{ Drugs } & \multicolumn{13}{|c|}{ Weight of plants (Mg) } \\
\hline & P1 & $\mathrm{P} 2$ & P3 & P4 & P5 & P6 & P7 & P8 & P9 & P10 & P11 & $\begin{array}{l}\text { Experimental } \\
\% * \text { RBGL }\end{array}$ & Predicted \\
\hline D1 & 40 & 40 & 35 & 30 & 40 & 50 & 25 & 55 & 65 & 45 & 75 & 82 & 79.11 \\
\hline D2 & 75 & 30 & 50 & 40 & 45 & 35 & 65 & 35 & 45 & 40 & 40 & 93 & 90.23 \\
\hline D3 & 65 & 50 & 30 & 35 & 35 & 40 & 75 & 45 & 50 & 30 & 45 & 91 & 85.43 \\
\hline D4 & 55 & 60 & 40 & 25 & 55 & 60 & 55 & 35 & 30 & 20 & 65 & 85 & 86.78 \\
\hline D5 & 60 & 55 & 25 & 40 & 60 & 55 & 35 & 55 & 65 & 30 & 20 & 87 & 88.67 \\
\hline D6 & 50 & 65 & 35 & 30 & 40 & 35 & 45 & 75 & 45 & 50 & 30 & 82 & 81.79 \\
\hline D7 & 25 & 55 & 60 & 55 & 60 & 40 & 65 & 30 & 20 & 35 & 55 & 80.5 & 82.31 \\
\hline
\end{tabular}

*RBGL: Reduction in Blood Glucose Level 


\section{Genetic Algorithm}

The prediction of biological activity of a chemical compound from its compositional features, representing its physicochemical properties, plays an important role in drug discovery, design and development. Since the biological data is highly non-linear, the machine-learning techniques have been widely used for modeling it. In the present work, Genetic Algorithm (GA) is used to develop computational prediction models on a dataset of antidiabetic plants. Gas is general-purpose evolutionary algorithms that can be used for optimization (Sachan et al., 2009). In a GA, each population member is a potential solution, which is equal to its population size. GAs were first introduced by Holand (Yadav et al., 2005) which is a search algorithm.
These are stochastic optimization method and provide a powerful technology to perform random searches in a large problem space. An introduction and overview of the application of GAs are reported by Venkatasubramanian and Sundaram (Zupan and Gasteiger, 1999).

Presently both GA was applied to predict the bioactivity of the optimized herbal drug. The algorithm is shown in Fig. 1.

The system achrtitecure is represented in Fig. 2. X1, $\mathrm{X} 2, \ldots \mathrm{X} 11$ are the compounds responsible for the effective drug and optimized drug have better performance with RBGL value. The main objective of this proposed method to select the concentration value of the compound in such a way to achieve high RBGL value.

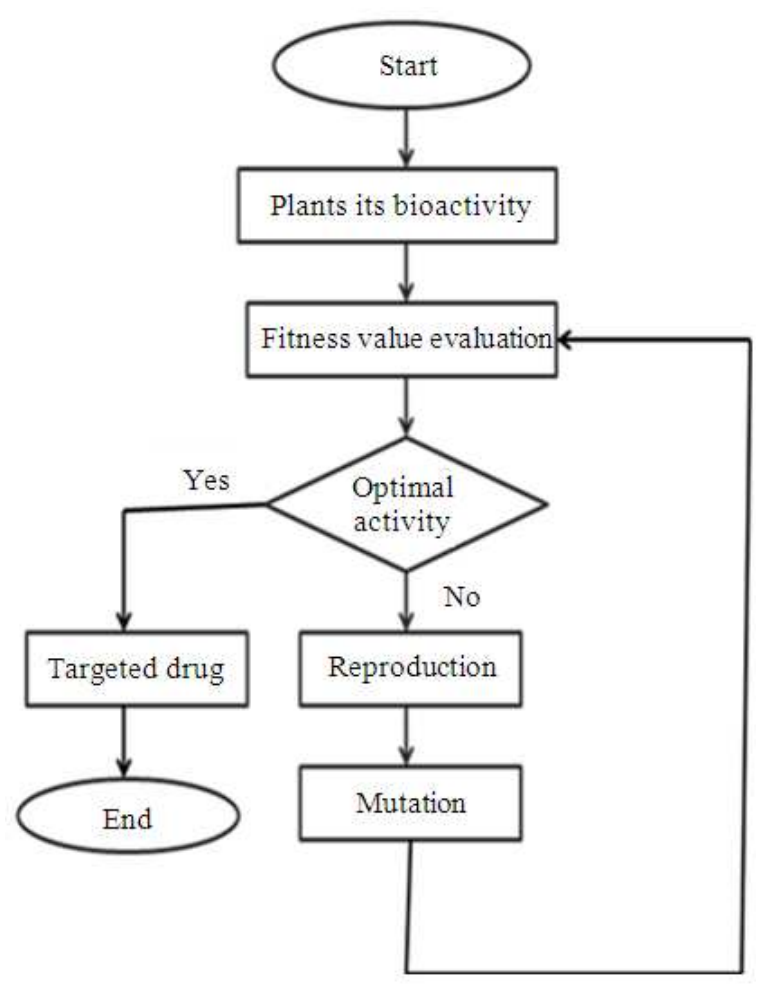

Fig. 1. Algorithm for optimal drug design parameter

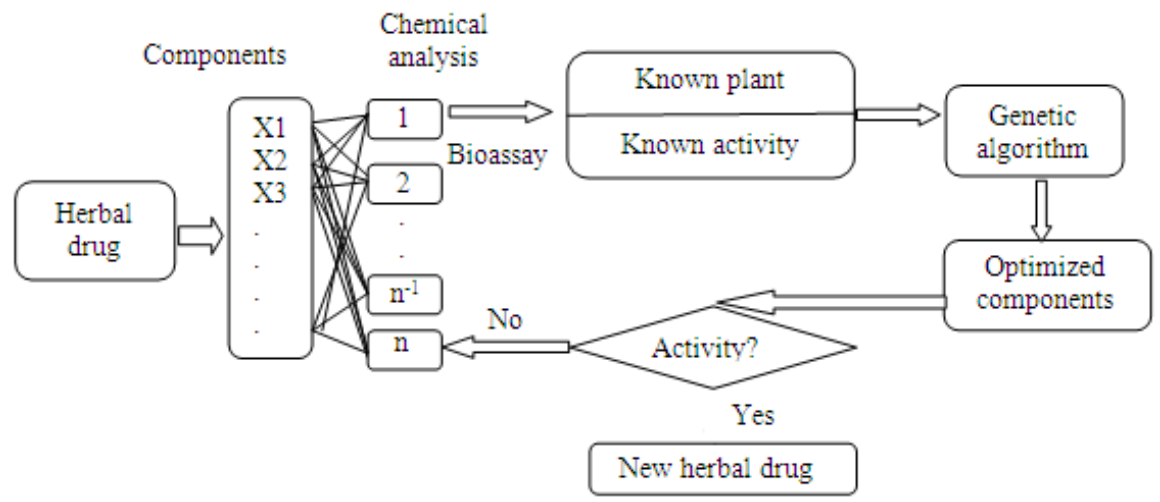

Fig. 2. An illustration for herbal drug design to quantitative Plant Activity Relationship (QPAR) 


\section{Result Analysis}

The algorithm was implemented using in house $\mathrm{C}$ programme. All calculations were carried out on a computer with a $2.0 \mathrm{GHz}$ Core to Duo processor. The simulation was performed using predictive GA. The weight of the plant extracts, dose and its activities are inter related which was binary coded here. Two uniform cross over having probability of 65 and $0.02 \%$ mutation rate applied in this study. The results were obtained after 1000 iterations. Table 1 shows the bioactivity of the individual plant. The Fig. 3 shows the reduction in blood glucose level of individual plants.

\section{Discussion}

It is found from the literature (Ezike et al., 2010; Monago and Alumanah, 2005; Okpanachi et al., 2010; Mazumder et al., 2009; Routhu et al., 2005; Sachan et al., 2009; Arambewela et al., 2005; Dixit et al., 1986; Niedzielski and Swift, 2002; Qureshi et al., 2009; Satyanarayana et al., 2004) that, it is very complex task to make optimized drug to maintain high RBGL.

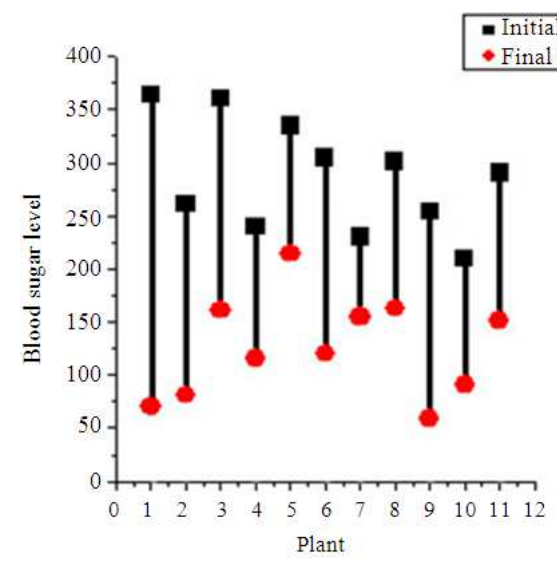

Fig. 3. Graph showing the initial and final blood sugar level

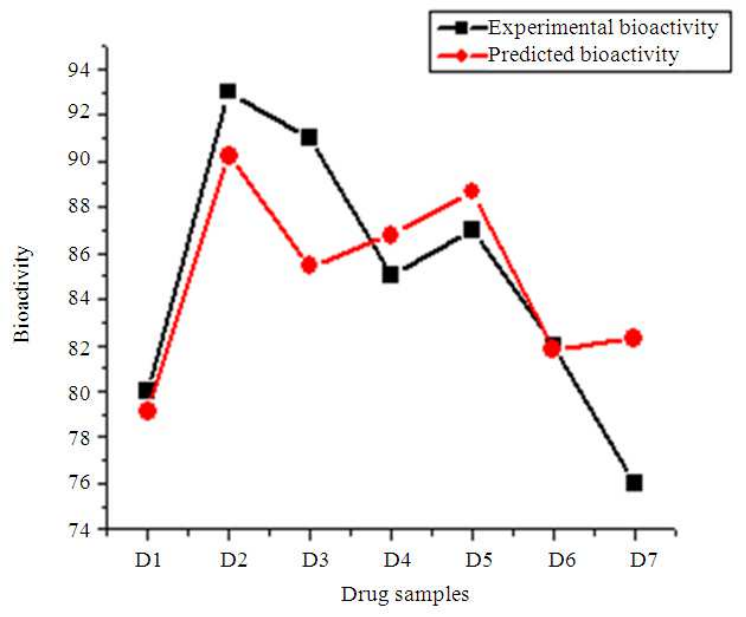

Fig. 4. Graph showing the experimental and predicted bioactivity of drug samples
As it is purely biological application, many physical experiments are required before any application of mathematics and computer. Some optimization methods are applied, but the result obtain is not good compare to the current application of genetic algorithm. The main objective of this proposed methodology, to find the appropriate weight of the eleven biological compounds to maintain the high RBGL value.

Table 2 shows the bioactivity of 7 no of drug samples having $500 \mathrm{mg}$ weight each. The weight of individual plant extracts of each individual drug is also shown in the Table 2. Further the predicted bioactivities are also given against each drug. It is observed that the drug sample no 2 has the highest bioactivity which is the optimized drug. The Fig. 4 shows the actual and predicted bioactivity of 7 drugs consisting of 11 plants at different ratios. The compositions of the drug sample no 2 is also the optimized compositions to get the highest bioactivity. The multiple herbal when combined together at different ratios gives more effectiveness as shown in the Table 2. This is because of combined effect of the compounds present in different plants. Here GA plays a major role to predict combined effect of the multiple herbal having different compositions. The dose toxicity factor of the plant has not been considered here which can be taken as constraints.

\section{Conclusion}

The complete simulation has not been done for final optimization. The present work is just a preliminary one to study only the concept of drug design using genetic algorithm approach. Further work will be extended for the development of drug, which can reduce, both time and cost. The soft computing approach can be extended for any kind of diseases. These models can be useful for predicting the biological activity of new untested drug for identifying new active compounds in the traditional drug.

\section{Acknowledgement}

The authors are highly indebted to Dr. Tirupati Panigrahi, Chairman of Hi-Tech Medical College and Hospital, Bhubaneswar, Odisha, India for his constant help and inspiration. The technical help furnished by the technical staffs of Research and Development Center is also deeply acknowledged.

The authors express their gratitude to the publisher of Journal of Computer Science and anonymous reviewers for their constructive suggestions that helped to improve the literal and technical contents of the manuscript.

\section{Funding Information}

The authors have no support or funding to report. 


\section{Author's Contributions}

All authors equally contributed in this work.

\section{Ethics}

The article is original and contains unpublished material. The corresponding author confirms that all the other authors have read the manuscript and approved it for publication and no ethical issues involved.

\section{References}

Arambewela, L.S.R., L.D.A.M. Arawwawala and W.D. Ratnasooriya, 2005. Antidiabetic activities of aqueous and ethanolic extracts of Piper betle leaves in rats. J. Ethnopharmacol., 102: 239-245.

DOI: 10.1016/j.jep.2005.06.016

Chan, E., M. Tan, J. Xin, S. Sudarsanam and D.E. Johnson, 2010. Interactions between traditional Chinese medicines and Western therapeutics. Current Opin. Drug Discovery Devel., 13: 50-65. PMID: 20047146

Dixit, V.P., R. Sinha and R. Tank, 1986. Effect of neem seed oil on the blood glucose concentration of normal and alloxan diabetic rats. J. Ethnopharmacol., 17: 95-98. DOI: 10.1016/0378-8741(86)90076-0

Ezike, A.C., P.A. Akah, C.C. Okoli and C.B. Okpala, 2010. Experimental evidence for the antidiabetic activity of cajanus cajan leaves in rats. J. Basic Clin. Pharm., 1: 81-84. PMID: 24825970

Grover, J.K., S. Yadav and V. Vats, 2002. Medicinal plants of India with anti-diabetic potential. J. Ethnopharmacology, 81: 81-100. DOI: $10.1016 / \mathrm{S} 0378-8741(02) 00059-4$

Heacht, P., 2002. High-through put screening to odds with informatics-driven chemistry. Current Drug Discovery.

Holland, J., 1975. Adaptation in Natural and Artificial Systems: An Introductory Analysis with Applications to Biology, Control and Artificial Intelligence. 1st Edn., Ann Arbor, University of Michigan Press, ISBN-10: 0472084607, pp: 183.

Ivorra, M.D., M. Paya and A. Villar, 1989. A review of natural products and plants as potential antidiabetic drugs. J. Ethnopharmacol, 27: 243-275. DOI: 10.1016/0378-8741(89)90001-9

Kavimanib, S., B. Kadalmanic, A.B.A. Ahmedd, M.A. Akbarshac and M.V. Rao et al., 2008. Antidiabetic activity of leaf and callus extracts of aegle marmelos in rabbit. Sci. Asia, 34: 317-321.

DOI: $10.2306 /$ scienceasia 1513-1874.2008.34.317
Mazumder, P.M., M. Farswan and V. Parcha, 2009. Hypoglycemic effect of ficus arnottiana Miq. Bark extracts on streptozotocin induced diabetes in rats. Nat. Product Radiance, 8: 478-482.

Monago, C.C. and E.O. Alumanah. 2005. An-tidiabetic effect of chloroform-methanol extract of abrus PI.ecutorius Linn seed in alloxan diabetic rabbit. J. Applied Sci. Environ., 9: 85-88.

Niedzielski, K. and L. Swift, 2002. Effect of coccinia indica on blood glucose levels in alloxan-induced diabetic mice. J. Biol. Res., 3: 1-5.

Okpanachi, A.O., A.B. Adelaiye, A.A.U. Dikko, M. Kabiru and A. Mohammed, 2010. Evaluation of the effect of aqueous-methanolic stem bark extract of acacia polyacantha on blood glucose levels of alloxan induced diabetic wistar rats. Int. J. Anim. Vet. Adv., 2: 59-62.

Qureshi, S.A., W. Asad and V. Sultana, 2009. The Effect of Phyllantus emblica Linn. On type II diabetes, triglycerides and liver-specific enzymes. Pak. J. Nutr., 8: $125-128$. DOI: $10.3923 /$ pjn.2009.125.128

Routhu, K., R. Alluri and E.K. Kilari, 2005. Hypoglycemic and antihyperglycemic effect of Gmelina asiatica LINN. In normal and in alloxan induced diabetic rats. Biol. Pharm. Bull., 28: 729-732. PMID: 15802818

Sachan, N.K., Y. Kumar, S. Pushkar, R.N. Thakur and S.S. Gangwar et al., 2009. Anti-diabetic potential of alcoholic and aqueous extracts of ficus racemosa Linn. Bark in normal and alloxan induced diabetic rats. Int. J. Pharm. Sci. Drug Res., 1: 24-27.

Satyanarayana, T., T. Sarita, M. Balaji, A. Ra-mesh and M.K. Boini, 2004. Antihyperglycemic and hypoglycemic effect of thespesia populnea fruit in normal and alloxan-induced diabetes in rabbits. Saudi Pharm. J., 12: 2-3.

Wang, Y., X. Wang and Y. Cheng, 2006. A computational approach to botanical drug design by modeling quantitative composition-activity relationship. Chem. Biol. Drug Des., 68: 166-172. DOI: $10.1111 / \mathrm{j} .1747-0285.2006 .00431 . \mathrm{x}$

Yadav, U.C.S., K. Moorthy and N.Z. Baquer, 2005. Combined treatment of sodium orthovanadate and Momordica charantia fruit extract prevents alterations in lipid profile and lipogenic enzymes in alloxan diabetic rats. Molecular Cellular Biochem., 268: 111-120. DOI: 10.1007/s11010-005-3703-y

Zupan, J. and J. Gasteiger, 1999. Neural Networks in Chemistry and Drug Design: An Introduction. 1st Edn., John Wiley and Sons, Inc., Weinheim, ISBN-10: 3527297782, pp: 380. 